\title{
Jodorowsky de carne y hueso
}

\author{
Leo Cayuela \\ chadamf@hotmail.com
}

\section{a modo de abstract}

...y Jodoroswky haciendo de Brujo actor chamánico en trance, induce al enfermo a la curación. En estas representaciones se incluye todo tipo de objeto que pueda tener un valor simbólico relacionado con el paciente y su enfermedad o su problema. El incluye algo de su propia cosecha, los brujos actúan en la oscuridad y el lo hace a plena luz y vestido de blanco, esto para que el enfermo participe conscientemente en el acto sabiendo que no hay trucos...

Me gusta mucho Alejandro Jodorowsky, he visto tres de sus cuatro películas, he leído varios de sus cómics entre ellos "El Incail Negro" fundamental en esta faceta de su obra desarrollada en París junto al dibujante Moebius, tengo cuatro libros escritos por él y uno de conversaciones que tuvo con el escritor francés Gilles Farcet. De estas facetas me quedo con las películas porque le conocí primero a través de ellas. Desde sus inicios eligió ser simbolista y ha desarrollado a través del tiempo un lenguaje puro y personal que refleja la esencia artística propia con la que él ha conectado. Por lo que después de conocer cualquiera de sus obras es difícil quedar intacto. Recuerdo que después de leer "Donde mejor canta un pajaro" estuve varios días afectado, me gusto mucho y me pareció terrible, era justo lo que esperaba de él en una novela. Uno decide entrar en su mundo visceral y pánico y lo vive a plenitud. Con el dramaturgo Arrabal y el dibujante Topor desarrolló el teatro pánico en los años sesenta. Y bajo esta etiqueta realizaron varios "happenings" que incluían grandes dosis de violencia. En el libro de conversaciones Alejandro comenta que cuando se planteaba realizar una obra de teatro o un happening siempre comenzaba por la violencia por que el mundo es violento y se llega a la paz después de pasar por la violencia. Por eso sus obras tienen una carga tremenda. Hoy en día se dedica a la psicomagia y para entender de qué va esto yo lo resumo como el espacio en el que él mezcla todo lo que ha conocido y experimentado. Es ante todo una disciplina artística terapéutica. Jodoroswky es un hombre de teatro, también ha sido mimo, como mimo desarrolló pantomimas para Marcel Marceau. Después de ir de gira con Marceau, su búsqueda artística y espiritual le llevo a Méjico, allí conoció a los más grandes magos que pueda uno imaginar, aquellos que operan con las manos en medio de penumbras, valiéndose de vísceras que hacen las veces de órganos que se extraen usando machetes en vez de bisturí y valiéndose del drama y una actuación histriónica que inducen al enfermo hacia la curación. Jodorowsky fue operado por una bruja eminente que ya es una leyenda: "Pachita". Le abrió el abdomen y le extrajo una piedra del riñón, él comenta que sintió un dolor indecible, vio su sangre llenar la mesa en la que estaba acostado y luego después de un curetaje, había sanado y no presentaba cicatriz alguna. Hay que agregar que al mismo tiempo Alejandro intentaba resolver sus problemas emocionales producidos por una relación difícil con su padre y que le llevo a estudiar muchas de las vertientes del psicoanálisis. En su autobiografía "La 
danza de la Realidad" comenta que ninguna le sirvió. Estas dos vertientes sobretodo son el origen de la psicomagia. El artista ha dicho que después de recibir los aplausos y convertirse en mito dentro del cine sintió una enorme necesidad de hacer algo por los demás. Se fue a Francia estudio el Tarot de Marsella y en una librería de Paris comenzó a hacer lecturas gratuitas a quien lo deseara. Estos serían sus primeros pasos hacia su particular forma de hacer terapias. Comenta que al entrar la persona a la que echaría en tarot, inmediatamente le hacia una radiografía en la que descubría su estado anímico, sexual, económico, familiar, etc. Entonces al echar el tarot daba algunos consejos para resolver los problemas planteados. Con el tiempo se dio cuenta que necesitaba ir más allá, entonces se planteo hacer algo parecido a lo que hacen los brujos que operan con las manos pero orientado hacia el teatro. A partir de allí surgen unas escenas en las que el enfermo vive una situación, la actúa, y Jodoroswky haciendo de Brujo actor chamánico en trance, induce al enfermo a la curación. En estas representaciones se incluye todo tipo de objeto que pueda tener un valor simbólico relacionado con el paciente y su enfermedad o su problema. El incluye algo de su propia cosecha, los brujos actúan en la oscuridad y el lo hace a plena luz y vestido de blanco, esto para que el enfermo participe conscientemente en el acto sabiendo que no hay trucos. En "La danza de la realidad" comenta varias de estas representaciones y sus resultados.

Jodorowsky ha venido a Barcelona varias veces a promocionar sus libros. Cada vez que pasa por el Fnac me entero al día siguiente. Sin embargo en su última visita el jueves 22 de abril si pude estar gracias a la llamada de un amigo que me avisa sus visitas cuando ya ocurrieron. Asistí con muchas expectativas. Mientras iba en autobús hacia el Fnac escuchaba a los que iban sentados detrás mío que también iban con grandes expectativas, yo pensé no vamos a caber. Llegué y había una cola que se salía hasta la diagonal, pregunte al securata si valía la pena hacer la cola, respondió que si, que el sitio era grande. Entre los últimos vi un hueco en la esquina izquierda cerca del micrófono y la silla en que el se colocaría y allí me coloque. Este lugar quedaba al lado de una puerta por la que me asomé y detecté el traje negro, los zapatos negros y la barriga de Jodorowsky. Me asome un poco más, le salude, el me devolvió el saludo y a los pocos minutos salió. De entrada dijo que no sabía de que hablaría, que nunca prepara nada y que tiene cuarenta y cinco minutos para conversar de su nuevo libro "Psicomagia" y contestar preguntas. Entonces se mando a hablar de todo un poco, de elefantes y su significado simbólico dentro del tantra, del peso de las neurosis de nuestros padres o abuelos en nosotros y de nosotros hacia nuestros hijos, de cómo solucionarlos según su método. Contó chistes, todos con contenido iniciático. Otro de sus libros se titula "La sabiduría de los chistes" e incluye el chiste de un loro que allí contó. De pronto me di cuenta que en ese caos estaba a su vez respondiendo a muchas de las preguntas que los que estábamos allí nos gustaría hacerle. Es un poco filósofo y aplica su filosofía sin problemas por ejemplo de pronto deja de hablar de su rollo con su padre y le pide a un joven del público que se levante y diga por que está allí. El joven dice que porque leyó "La danza de la realidad" y que su terapeuta le había avisado de la charla. Al parecer Jodorowsky intuye que el joven tiene un problema y le abraza paternalmente durante unos minutos, entonces le pregunta porque tiene esos zapatos. El joven se mira los zapatos, responde que porque le agradan, a Jodorowsky se le ocurre que esos zapatos le impiden avanzar en sus proyectos. Todos le miramos los zapatos y tienen la punta totalmente cuadrada. A continuación le receta que compre unos zapatos puntiagudos y esto le ayudará. Algunos aplauden, a mi parece todo muy divertido. Sigue hablando y dice que hay que sacar de cualquier situación lo que sea útil, ahí pienso que es lo que el ha hecho siempre. Entonces me fijo en mis zapatos veo que tienen la punta cuadrada y me los envío mi madre desde Venezuela. Será que mi madre me está saboteando desde Venezuela, mañana me compro unos zapatos puntiagudos. 
Regreso a la charla y algunos hacen preguntas. Un hombre expone su caso, él y su mujer tienen problemas en la cama, ella no puede alcanzar el orgasmo. El da tres posibles diagnósticos y recetas. Opción uno: ella tiene un bloqueo por estar enamorada del padre. Sugiere que él consiga ropa del padre y alguna otra cosa como su colonia y hagan el amor. Opción dos: ella tiene necesidad de serle infiel. Sugerencia: ella debe reservar habitación en un hotel sin que el lo sepa, luego debe mentirle y decir que tiene cita con el dentista. Entonces a la hora de la cita ella estará en el hotel y él irá allá disfrazado, puede ser de Motero, o de Paleta, o lo que quiera pero que sea fuerte, entonces llega a la habitación y sin hablar la posee con fuerza, con ganas, con morbo, sin hablar se retira y luego ella llega a casa y dice que viene del dentista, que todo bien, que le duele un poco y ninguno de los dos comenta lo del hotel. Opción tres: ambos tienen un componente homosexual, receta: vestirse el uno del otro y hacer el amor invirtiendo los papeles. Aquí pienso que pueden haber más opciones, y Jodorowsky casi respondiéndome dice que él intenta hacer lo que puede, y así lo hace cuando una mujer se para y le pide que le coloque las manos en la espalda para aliviarle un problema lumbar. El lo intenta, al ver que no lo logra le pide a dios que lo haga a través de él, dice que el no es un santo y no puede hacer más que eso. Allí pienso en la eficacia simbólica y todas las esperanzas que tenía esa mujer puestas en Jodorowsky. Pero lo cierto es que esto es una charla para presentar un libro, tal vez con todas las condiciones necesarias, previo análisis del árbol genealógico que él hace antes de la terapia, podrían tener más efectividad sus manos. El agrega que el dolor lo tiene en el lado derecho, el lado del padre, seguramente el dolor tiene su origen allí. Siguen las preguntas y las recetas. En esta parte detecto que está recetando lo mismo que ha recetado en otros casos que aparecen comentados en "La danza de la realidad". Aquí me doy cuenta que como él dice hace lo que puede y en un acto de promoción editorial es bastante. Finaliza el tiempo y viene la firma de libros, yo me voy pensando en el gusto de conocer a alguien a través de su obra y luego verle de carne y hueso y ver que no están separados. Desecho la idea de comprarme unos zapatos puntiagudos y me quedo con la frase de " saca lo que sea útil de cualquier situación ".

\section{Bibliografía:}

Jodorowsky, A. (1991). La trampa sagrada. Conversaciones con Gilles Farcet. Santiago de Chile: Ediciones Pedagógicas.

Jodorowsky, A. (1994). La sabiduría de los chistes. Méjico: Grijalbo.

Jodorowsky, A. (1998). Donde mejor canta un pajaro. Santiago de Chile: Dolmen Ediciones

Jodorowsky, A. (2001). La danza de la realidad. Madrid: Ediciones Siruela

\section{Formato de citación}

Cayuela, L. (2004). Jodorowsky de carne y hueso. Athenea Digital, 6. Disponible en http://antalya.uab.es/athenea/num6/cayuela.pdf 


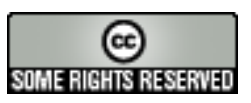

\section{Este texto está protegido por una licencia Creative Commons.}

Usted es libre de copiar, distribuir, exhibir y comunicar la obra bajo las siguientes condiciones:

Reconocimiento: Vd. debe reconocer y dar crédito al autor original.

NoComercial. Vd. no puede utilizar esta obra para fines comerciales.

NoDerivados. Vd. no puede alterar, transformar, o añadir nada a esta obra.

\section{Resumen de licencia}

$\underline{T e x t o ~ c o m p l e t o ~ d e ~ l a ~ l i c e n c i a ~}$ 